\title{
Le service public de l'eau en milieu rural au Sénégal : l'exemple de la communauté rurale de Moudéry
}

Thèse de Doctorat (PhD), Aix-Marseille Université, Université de Provence, 2011

\section{Clément Repussard}

\section{OpenEdition} Journals

Édition électronique

URL : http://journals.openedition.org/anthropodev/335

DOI : 10.4000/anthropodev.335

ISSN : 2553-1719

Éditeur

APAD - Association pour l'anthropologie du changement social et du développement

\section{Édition imprimée}

Date de publication : 1 septembre 2014

Pagination : 207-208

ISBN : 9791093476018

ISSN : 2276-2019

\section{Référence électronique}

Clément Repussard, « Le service public de l'eau en milieu rural au Sénégal : l'exemple de la communauté rurale de Moudéry », Anthropologie \& développement [En ligne], 40-41 | 2014, mis en ligne le 01 septembre 2016, consulté le 23 septembre 2020. URL : http://journals.openedition.org/ anthropodev/335; DOI : https://doi.org/10.4000/anthropodev.335

\section{(c) ()}

La revue Anthropologie \& développement est mise à disposition selon les termes de la Licence Creative Commons Attribution 4.0 International. 


\title{
Le service public de l'eau en milieu rural au Sénégal : l'exemple de la communauté rurale de Moudéry
}

\author{
Clément Repussard ${ }^{1}$ \\ Thèse de Doctorat (PhD), Aix-Marseille Université, \\ Université de Provence, 2011
}

\section{Résumé}

Cette thèse a pour objet la construction du service de l'eau potable en milieu rural à l'Est du Sénégal, à partir de l'exemple de quatre villages de la Communauté rurale de Moudéry, dans le département de Bakel. Le travail de terrain a été mené de 2008 à 2010 en même temps qu'un travail opérationnel dans un programme de développement mené par une ONG française. Depuis une position d'insider, ce sont donc les mécanismes socio-économiques et institutionnels de production d'un service public en contexte de développement aidé qui sont étudiés.

La délivrance de ce service au quotidien est resituée dans la longue durée historique. Les conditions de production et de fonctionnement du service sont ainsi mises en relation avec les processus de construction de l'Etat et les évolutions des sociétés villageoises, au premier rang desquelles l'émigration, mais aussi avec la succession des programmes internationaux d'accès à l'eau potable.

Le premier chapitre établit l'état des lieux des recherches en sciences sociales sur le service public de l'eau an Afrique de l'Ouest. Le second chapitre décrit I'histoire de la politique publique sénégalaise de l'eau en milieu rural depuis le début du XXe siècle. Le troisième chapitre analyse ensuite la diversité des services d'eau coexistant au niveau local. Puis, dans le quatrième chapitre, la fragmentation des configurations de délivrance du service public de l'eau est décrite. Le cinquième chapitre décrit comment cette fragmentation se retrouve au niveau villageois, à partir de quatre études de cas villageoises, qui retracent les évolutions des réseaux d'eau potable depuis les années 1980 et l'enracinement de la gestion du service dans les structures sociales villageoises. Le dernier chapitre se concentre sur l'articulation des différents espaces sociaux et politiques de l'eau. Plusieurs types de services de l'eau, plus ou moins publics, mettent en jeu des collectifs différents dans les espaces villageois. Des échelles de citoyenneté différentes s'articulent ainsi de façon complémentaire, définissant et actualisant des droits et des devoirs rattachant les individus à des collectifs distincts.

\footnotetext{
${ }^{1}$ E-mail : clementrepussard@gmail.com
} 
Au final, les processus à l'œuvre (construction étatique, décentralisation, émigration, aide au développement, recomposition des pouvoirs locaux, etc.) n'aboutissent pas à une construction d'un service public unifié. Plusieurs services de l'eau, ancrés dans des espaces sociaux différents, parfois superposés, sont issus de l'enchevêtrement plus ou moins pragmatique des initiatives d'une diversité d'acteurs. Le rôle des pouvoirs publics en particulier s'avère plus proche d'un courtage institutionnalisé au sein des mécanismes d'allocation des projets de développement, que de la régulation du service ou la maîtrise d'ouvrage des infrastructures techniques. 